
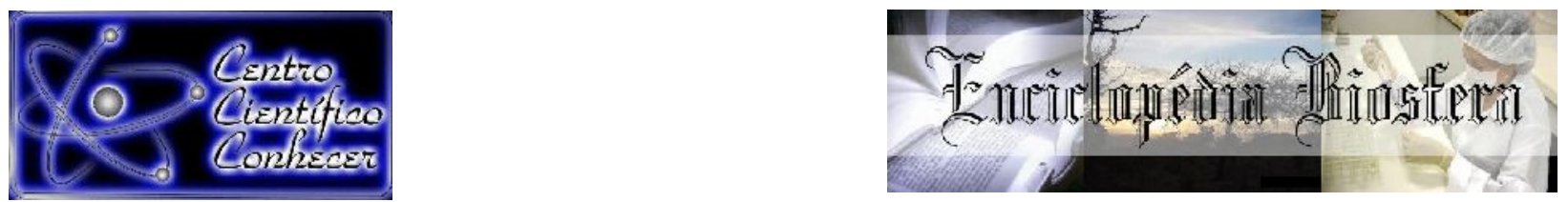

\title{
O PROGRAMA DE AQUISIÇÃO DE ALIMENTOS (PAA): ESTUDO DE CASO SOBRE LIMITAÇÕES E AVANÇOS NA MODALIDADE COMPRA INSTITUCIONAL EM BELÉM, ESTADO DO PARÁ
}

\author{
Ana Paula Macedo de Jesus ${ }^{1}$ Amanda da Silva Nogueira1 Ruth Helena Cristo \\ Almeida² Marcos Antônio Souza dos Santos² \\ ${ }^{1}$ Graduandas do Curso de Agronomia, Instituto Socioambiental e dos Recursos Hídricos, \\ Universidade Federal Rural da Amazônia, Belém/PA \\ 2Professores Doutores do Instituto Socioambiental e dos Recursos Hídricos, Universidade \\ Federal Rural da Amazônia, Belém/PA \\ (ruth.almeida@ufra.edu.br) \\ Recebido em: 22/09/2018 - Aprovado em: 23/11/2018 - Publicado em: 03/12/2018 \\ DOI: 10.18677/EnciBio_2018B123
}

\begin{abstract}
RESUMO
O Programa de Aquisição de Alimentos - PAA é uma política pública de incentivo ao desenvolvimento da agricultura familiar que possibilita a ampliação dos canais de comercialização e geração de renda, na qual as modalidades de Compra com Doação Simultânea (CPR - Doação) e Compra Institucional (Cl), representam oportunidade para que os agricultores comercializem sua produção em mercados institucionais. O objetivo do artigo foi avaliar a forma como se distribui a alocação de recursos do PAA no estado do Pará e o acesso ao programa, na modalidade $\mathrm{Cl}$ tomando como estudo de caso o município de Belém. A pesquisa foi desenvolvida por meio de uma abordagem quali-quantitativa exploratória, fundamentada em dados secundários fornecidos pela Superintendência Regional da Companhia Nacional de Abastecimento no estado do Pará (CONAB/SUREG-PA) e para identificar as dificuldades para a execução do $\mathrm{PAA}-\mathrm{Cl}$ foram entrevistados os gestores de cinco instituições federais. Constatou-se a baixa participação das mulheres no programa, além da diminuição no número de fornecedores que reduziu à medida que a quantidade de municípios se desligou do PAA. As principais limitações para a funcionalidade do $\mathrm{PAA}-\mathrm{Cl}$ na cidade de Belém-PA relacionam-se aos aspectos logísticos, operacionais e a maiores articulações entre os órgãos públicos e os produtores. Conclui-se que existem muitos entraves para implementação e desenvolvimento dessa política em função da necessidade de maior diálogo entre o governo e os produtores.
\end{abstract}

PALAVRAS-CHAVE: Agricultura familiar, Amazônia, Mercados institucionais, Segurança alimentar.

\section{THE FOOD ACQUISITION PROGRAM (PAA): CASE STUDY ON LIMITATIONS AND ADVANCES IN THE INSTITUTIONAL PURCHASE MODEL IN BELÉM, STATE OF PARÁ}

\author{
ABSTRACT \\ The Food Acquisition Program (PAA) is a public policy to encourage the \\ development of family agriculture, which allows the expansion of commercialization \\ and income generation channels, in which the Simultaneous Donation (CPR -
}


Donation) and Institutional Purchase ( $\mathrm{Cl}$ ) represent an opportunity for farmers to market their production in institutional markets. The objective of this article was to evaluate the way in which the allocation of PAA resources in the state of Pará and access to the program are distributed in the $\mathrm{Cl}$ mode, taking as a case study the municipality of Belém. The research was developed through a qualitative approach (CONAB / SUREG-PA) and to identify the difficulties for the execution of the PAA-CI, the managers of five federal institutions were interviewed. The low participation of women in the program was verified, as well as the decrease in the number of suppliers that reduced as the number of municipalities disconnected from the PAA. The main limitations to PAA-Cl's functionality in the city of Belém-PA are related to logistical, operational and greater articulations between public agencies and producers. It is concluded that there are many obstacles to the implementation and development of this policy due to the need for greater dialogue between government and producers.

KEYWORDS: Family agriculture, Amazon, Institutional markets, Food security.

\section{INTRODUÇÃO}

As políticas Públicas associadas ao meio rural, a partir da década de 1990, passaram a receber maior importância no Brasil, possibilitando melhor reconhecimento à Agricultura Familiar, considerando inicialmente a implementação do Programa Nacional de Fortalecimento da Agricultura Familiar (PRONAF) (LEMOS; LIMA, 2014; CUNHA et al., 2017). Em meio à busca por maior desenvolvimento do segmento de agricultores familiares, a partir da inserção em mercados ocorreu, em 2003, a criação do Programa de Aquisição de Alimentos (PAA) (BRASIL, 2003; SARON et al., 2017).

O PAA foi instituído pelo art. 19 da Lei no 10.696, de 02 de julho de 2003, e compõe o Sistema Nacional de Segurança Alimentar e Nutricional - SISAN, tendo como principais objetivos incentivar a agricultura familiar, promover a inclusão socioeconômica e o desenvolvimento sustentável, gerando renda, além de viabilizar acesso à alimentação de qualidade e em quantidade suficiente (BRASIL, 2018).

Segundo a Companhia Nacional de Abastecimento (CONAB, 2017), o PAA possibilita a aquisição dos produtos oriundos da agricultura familiar, em momento adequado, por preço compensador, trazendo segurança e incentivo ao pequeno agricultor, que pode passar a planejar suas atividades pela perspectiva de um horizonte maior de previsibilidade.

Atualmente o PAA é operacionalizado pela Companhia Nacional de Abastecimento (CONAB) através de seis modalidades sendo: Compra da Agricultura Familiar para Doação Simultânea (CPR - Doação), Compra Direta da Agricultura Familiar (CDAF), Formação de Estoques pela Agricultura Familiar (CPR - Estoque), Incentivo à Produção e consumo de Leite (PAA - Leite), Compra de Sementes e Compra Institucional (CI) (BRASIL, 2018).

A modalidade CPR - Doação objetiva atender demandas locais de suplementação alimentar de cidadãos em situação de insegurança alimentar e nutricional. Incentiva a produção local para o atendimento de entidades da rede socioassistencial, aos equipamentos públicos de alimentação e nutrição (BRASIL 2014).

O PAA foi atualizado por meio da Lei 12.512/2011, de 14 de outubro de 2011 que no artigo 17 dispensou o uso da licitação para aquisição de produtos dos beneficiários fornecedores. Com o decreto $n^{0}$ 7.775, de 4 de julho de 2012 foi viabilizada a criação da modalidade Compra Institucional, atualizada pelo decreto $\mathrm{n}^{\circ}$ 
8.293 de 12 de Agosto de 2014. Ademais, o decreto $n^{\circ} 8.473$ de junho de 2015 estabeleceu que todos os órgãos federais que compram alimentos devem comprar $30 \%$ de agricultores familiares (BRASIL, 2011; BRASIL , 2016).

No caso da Compra Institucional, o objetivo é garantir que estados, municípios e o Distrito Federal possam comprar alimentos voltados ao atendimento das demandas de alimentos por parte da União. Por esta modalidade poderão ser abastecidos hospitais públicos, quartéis, presídios e restaurantes universitários, dentre outros (BRASIL, 2014).

Pela importância do PAA como instrumento de política pública que interliga agricultores familiares com os mercados institucionais gerados por órgãos do serviço público o objetivo deste artigo foi avaliar a forma como se distribui o PAA pelo estado do Pará, e como está ocorrendo o acesso ao programa por agricultores familiares do município de Belém, mais especificamente na modalidade compra institucional.

\section{MATERIAL E MÉTODOS}

Este artigo apresenta uma abordagem exploratória e explicativa sobre o funcionamento do PAA no estado do Pará, verificando-se as dificuldades existentes na funcionalidade da política via modalidade $\mathrm{Cl}$ no município de Belém.

Foram utilizados dados secundários obtidos a partir de documentos oficiais com a disponibilidade de relatório gerencial contendo informações como municípios, cooperativas, organização de mulheres, grupos prioritários, quantidade comercializada, valor da produção e número de agricultores participantes do PAA entre os anos de 2009 e 2017 que foram fornecidos pela CONAB/SUREG-PA.

Os valores dos contratos foram atualizados para eliminar o efeito da inflação, empregando-se a calculadora do cidadão utilizando o Índice Geral de Preços Disponibilidade Interna (IGP-DI) na correção de valores, adotando como período base o mês de dezembro de 2017 (BRASIL, 2018). Todos os dados foram compilados em planilha do Microsoft Excel versão 2010 e representados por meio de tabelas os quais serviram de base para análise e interpretações.

Os dados qualitativos relativos às dificuldades encontradas no mercado de $\mathrm{Cl}$ foram coletados entre os meses de abril a julho de 2018 na região metropolitana de Belém-Pa, por meio de um roteiro de entrevista semi-estruturada com o total de 14 perguntas abertas realizadas pessoalmente com os representantes de três instituições federais, sendo: Universidade Federal do Pará (UFPA), $2^{\circ}$ Batalhão de Infantaria de Selva Belém-PA e Instituto Federal do Pará IFPA/Campus Belém.

Levantando-se informações tais como: o ano de lançamento do edital, entendimento da legislação, os beneficiários inscritos, quantidade de alimentos solicitados, qualidade dos produtos recebidos e posição das instituições quanto a lei que estabelece a compra dos $30 \%$ da agricultura familiar e suas vantagens e suas desvantagens.

Também, realizou-se contato com outras duas instituições federais que ainda não haviam realizado a compra via PAA, foram: Universidade Federal Rural da Amazônia (UFRA) e $4^{\circ}$ Distrito Naval da Marinha do Brasil . A entrevista com o representante da UFRA foi realizada na própria instituição, enquanto que o Comando do $4^{\circ}$ Distrito Naval da Marinha do Brasil respondeu ao roteiro via e-mail, com perguntadas que abordavam sobre a existência de restaurantes e conhecimentos sobre o PAA e do Decreto no 8.473/2015..

Após as entrevistas com os gestores das cinco instituições para o desencadeamento da análise descritiva e discussões, buscou-se o anonimato, para 
aquelas que lançaram edital e compra para aquisição de produtos via PAA-CI, utilizou-se a seguinte classificação I1 (Instituição um), I2 (Instituição dois) e I3 (Instituição três) e para aquelas que ainda não realizaram compra via PAA-Cl utilizou-se 14 (instituição quatro) e 15 (Instituição cinco).

\section{RESULTADOS E DISCUSSÃO}

\section{EVOLUÇÃO DOS RECURSOS DO PAA CPR - DOAÇÃO NO ESTADO DO PARÁ}

Entre os anos de 2009 a 2017, dos 144 municípios do estado do Pará o PAA foi acessado por cerca de 78 municípios. Deste total, foram beneficiadas 164 Cooperativas/Associações, sendo cinco gerenciadas e com foco em mulheres (Tabela 1). Injetou na agricultura familiar paraense um montante de $R \$$ 32.825.032,56, com os mais variados tipos de produtos. Segundo a SUREG-PA, o Pará é um dos estados onde se tem uma das maiores diversidades de produtos adquiridos pelo programa a nível nacional (CONAB, 2018).

O PAA hoje está difundindo em todo o país, o estado do Pará concentra a maior parcela dos projetos na região norte. A CONAB/SUREG-PA é responsável pela operacionalização do PAA no estado do Pará e o programa atende hoje mais de 50 municípios. O cumprimento das exigências burocráticas é a maior dificuldade enfrentada pelos agricultores familiares, pois a compra é feita por licitação através das associações e/ou cooperativas, porém esta tem que comprovar que os participantes das propostas são agricultores familiares, através das Declarações de Aptidão ao PRONAF (DAP) e a certificação das associações/cooperativas (CONAB, 2018).

O Relatório gerencial elaborado pela CONAB/SUREG-PA apresenta em detalhes os dados relativos ao funcionamento do PAA no município, número de cooperativa e associações, número de organização de mulheres, quantos grupos prioritários participam, quantidade comercializada, valor da produção e número de agricultores participantes do Programa.

Quanto à participação no programa do estado do Pará, observou-se que houve uma evolução nos anos de 2009 a 2012 ocorrendo maior atuação das Cooperativas/Associações e logo depois no período de 2013 a 2016 houve uma diminuição, essa redução ocorreu com o número de fornecedores e municípios, especificamente no ano de 2013. Porém referindo-se ao número de organização de mulheres não foi verificada maior participação, devido ter pouca visibilidade e acesso ao programa.

Diante disso, Cavalcanti et al., (2017) observaram que em todas as regiões do país o programa registrou diminuição, que o número de fornecedores reduziu-se à medida que a quantidade de municípios se desligou do PAA, especificamente entre os anos de 2012 e 2013. Segundo o IPEA (2015) a baixa realização do PAA em 2013 pode ser resultado do processo de redefinição do papel do Ministério do Desenvolvimento Social no programa, como a substituição dos modelos, retirando a participação das cooperativas e associações. Nota-se ainda a baixa visibilidade e participação das mulheres no PAA como foi observado ao longo dos anos de 2009/2013/2017. 
TABELA 1 - Dados PAA - Doação Simultânea no Pará de 2013 - 2017.

\begin{tabular}{c|c|c|c|c}
\hline Anos & $\begin{array}{c}\text { Municípios } \\
\text { Total }\end{array}$ & $\begin{array}{c}\text { Fornecedores- } \\
\text { Total }\end{array}$ & $\begin{array}{c}\text { Cooperativa/Associação } \\
\text { Proponentes } \\
\text { Total }\end{array}$ & $\begin{array}{c}\text { Org de Mulheres } \\
\text { Proponentes } \\
\text { Total }\end{array}$ \\
\hline 2009 & 8 & 64 & 9 & 0 \\
2010 & 42 & 1.348 & 48 & 1 \\
2011 & 40 & 1.312 & 51 & 2 \\
2012 & 45 & 2.111 & 64 & 1 \\
2013 & 3 & 110 & 4 & 0 \\
2014 & 9 & 308 & 9 & 2 \\
2015 & 10 & 304 & 10 & 1 \\
2016 & 10 & 407 & 12 & 1 \\
2017 & 24 & 745 & 30 & 0 \\
\hline
\end{tabular}

Fonte: CONAB/SUREG/PA.

Esses dados são referentes à execução da modalidade CPR - Doação, por meio do relatório gerencial realizado pelo CONAB/SUREG-PA. Os primeiros registros referentes ao PAA no estado datam do ano de 2009, quando foram comercializadas quase 400 toneladas de alimentos, somando um total de $R \$$ $352.511,82$ e 64 agricultores participantes.

Nos anos de 2009-2017 foram entregues no total $15.442 .691,00 \mathrm{~kg}$ de produtos oriundos da agricultura familiar com um montante $R \$ 40.762 .442,53$. Cada participante recebeu em média $\mathrm{R} \$ 11.914,65$ de repasses individuais, o número de agricultores variou de um ano para o outro, totalizando 6.709, sendo 2.249 mulheres nos anos de 2009-2017, com o máximo registrado no ano de 2012, com 2.111 e 656 mulheres participantes. Observou-se que o número de mulheres cresceu ao longo dos anos, mas somente a partir do ano de 2012 começou a ser mais expressivo comparado com os demais. Verificou-se que houveram variações nos valores com o passar dos anos, seja para mais ou para menos (Tabela 2).

Segundo Cavalcanti et al., (2017) os valores recebidos na região Norte, nos anos de 2011 a 2013, foi aquele em que os fornecedores que menos receberam recursos do programa, quando comparados aos fornecedores do Sul foram os que menos sofreram com as oscilações do PAA, destacou-se com o maior valor médio nos anos de 2011 a 2014. No ano de 2012 passou a vigorar o decreto № 7.775 o qual estabelece que as mulheres sejam um grupo prioritário. Este decreto regulamenta o artigo 19 da Lei $n^{\circ} 10.696$, de julho de 2003, que criou o Programa de Aquisição de Alimentos, e no inciso III e V, do parágrafo 4, artigo 4, deste decreto dizem que "§ 3ำ A participação de mulheres, dentre os beneficiários fornecedores, deverá ser incentivada. $\S 5^{\circ}$ Dentre as organizações aptas a participar do Programa, serão priorizadas as constituídas por mulheres."

O Grupo Gestor do Programa de Aquisição de Alimentos (GGPAA) por sua vez buscando fomentar o acesso de mulheres ao Programa de Aquisição de Alimentos tomou algumas medidas, pela resolução no 44, de agosto de 2011. Destaca-se a importância de reconhecer o trabalho feminino e sua contribuição na economia rural e na segurança alimentar e nutricional como estratégia de promoção da igualdade entre os gêneros. Neste sentido observou-se um esforço do Governo Federal em inserir um maior contingente de mulheres no PAA, pois pode-se observar uma grande masculinização no programa.

TABELA 2 - Dados PAA - Doação Simultânea no Pará de 2009 - 2017. 


\begin{tabular}{c|c|c|c|c|c}
\hline Anos & $\begin{array}{c}\text { Fornecedores- } \\
\text { Total }\end{array}$ & Mulheres & $\begin{array}{c}\text { Quantidade } \\
(\mathbf{K g})\end{array}$ & *Valor Real (R\$) & $\begin{array}{c}\text { Valor por } \\
\text { Fornecedor }\end{array}$ \\
\hline 2009 & 64 & 14 & $382.953,00$ & $\mathrm{R} \$ 352.511,82$ & $\mathrm{R} \$ 5.508,00$ \\
2010 & 1.348 & 305 & $2.182 .039,00$ & $\mathrm{R} \$ 7.638 .556,70$ & $\mathrm{R} \$ 5.666,59$ \\
2011 & 1.312 & 309 & $2.308 .485,00$ & $\mathrm{R} \$ 7.243 .092,61$ & $\mathrm{R} \$ 5.520,65$ \\
2012 & 2.111 & 656 & $3.580 .746,00$ & $\mathrm{R} \$ 11.052 .375,09$ & $\mathrm{R} \$ 5.235,61$ \\
2013 & 110 & 61 & $456.930,00$ & $\mathrm{R} \$ 676.563,10$ & $\mathrm{R} \$ 6.150,57$ \\
2014 & 308 & 172 & $1.269 .637,00$ & $\mathrm{R} \$ 2.445 .684,67$ & $\mathrm{R} \$ 7.940,53$ \\
2015 & 304 & 148 & $1.164 .429,00$ & $\mathrm{R} \$ 2.453 .692,21$ & $\mathrm{R} \$ 8.071,36$ \\
2016 & 407 & 199 & $1.460 .659,00$ & $\mathrm{R} \$ 3.170 .020,96$ & $\mathrm{R} \$ 7.788,75$ \\
2017 & 745 & 385 & $2.636 .813,00$ & $\mathrm{R} \$ 5.729 .945,37$ & $\mathrm{R} \$ 7.691,20$ \\
\hline
\end{tabular}

Fonte: CONAB/SUREG/PA.

*Nota: Valores em R\$ corrigidos pelo IGP-DI, Base: Dezembro de 2017.

\section{PAA COMPRA INSTITUCIONAL EM BELÉM: LIMITAÇÕES E AVANÇOS}

Observou-se que mesmo que o decreto $\mathrm{n}$ - 8.473 tenha sido lançado em 22 de junho de 2015 e entrado em vigor em 1 de janeiro de 2016, das três instituições entrevistadas que adquiriram alimentos por meio do PAA-CI, apenas uma lançou edital neste ano, a I1 (especificamente em novembro de 2016) as demais lançaram apenas no ano de 2017, justificando-se o fato do recurso financeiro ter sido disponibilizado apenas nesta data.

Sobre a compreensão destas legislações os entrevistados não demonstraram maiores dificuldades, apenas algumas dúvidas por se tratar de algo novo, mas que seria uma questão de adaptação, sugerindo-se por um deste maior esclarecimento quanto aos grupos prioritários.

Quando interrogados se houve priorização no momento da seleção por categorias, apenas a 12 mencionou a decorrência da prioridade para os agricultores familiares, já que, inicialmente o objetivo deles seria adquirir alimentos produzidos por estes. Isto reafirma a importância que vem sendo atribuída à agricultura familiar e as suas organizações, frente a questões como a Segurança Alimentar e Nutricional (COSTA et al., 2015; MARTINELLI et al., 2015).

Nas chamadas públicas realizadas pelas 11 e 12 foram inscritos tanto beneficiárias fornecedoras quanto organizações fornecedoras. Contudo selecionaram-se associações e cooperativas. Sobre o assunto Martinelli et al., 2015 afirmam que, por meio destas existe maior facilidade para o acesso aos mercados institucionais.

Outra questão levantada refere-se à entrega dos produtos na data solicitada pela parte contratante, visto que, as 12 e 13 disseram não receber os produtos demandados na data requerida, podendo-se associar a estes fatos a questão de planejamento e implantação do processo produtivo e ao escoamento de mercadorias. Como descrito por Costa et al., (2015) no que se refere a cooperativas da agricultura familiar, fatores como assistência técnica, adequação sanitária, gestão e logística são entraves para a participação desse público em políticas públicas.

Apenas a 12 afirmou ter devolvido alguns dos itens demandados, pois os mesmos não atendiam a especificação do edital, quanto à qualidade dos alimentos, as demais disseram não encontrar dificuldades quanto a este assunto. Enquanto a I3 relatou ter adquirido alimentos de ótima qualidade, quando comparado com produtos comprados de outros fornecedores (não sendo descritos como agricultores familiares).

A 13 apontou como principal problema durante a aquisição dos gêneros alimentícios o preço atribuído aos produtos oriundos da agricultura familiar, observando-se preços mais elevados quanto comparados a outros fornecedores. 
Sobre isto, sabe-se das despesas que os produtores encontram para realizar a produção, dispondo muitas vezes de infraestruturas insuficientes para trabalho o que dificulta o acesso, pois os custos operacionais para a participação em políticas públicas como o Programa Nacional de Alimentação Escolar (PNAE) e PAA são arcados pelos produtores rurais, sem renumeração por parte do governo (COSTA et al., 2015).

Percebeu-se que as principais dificuldades apontadas pelos representantes das instituições relacionam-se ao apoio para o desenvolvimento das políticas públicas que não se resumem apenas na formulação da lei, mas que requer maior assistência técnica, formulação de projetos, parcerias entre as secretárias (federais, governamentais e municipais) em prol dos produtores rurais, tal como disponibilidade de estrutura para a produção.

Simão et al. (2017) relataram sobre a eficácia do PAA, constataram que um dos grandes entraves é a entrega dos produtos aos beneficiários, de forma que, a maioria dos proponentes participantes tendem a se deslocar da zona rural para a cidade para então realizar a entrega dos alimentos, tornando-se problema, já que, os mesmos não dispõe de veículos próprios, o que eleva os custos devido a contratação de transporte.

Sobre isso Saron et al. (2017), por sua vez, reforçam a importância quanto a melhoria da infraestrutura no campo, a amplificação e aperfeiçoamento da extensão rural e assistência técnica, além da capacitação dos agricultores e dos técnicos envolvidos. Adicionalmente a existência de fiscais e técnicos para acompanhamentos das ações governamentais e o estímulo a parcerias entre poder público e associações e cooperativas, afim de financiamentos para aquisição de insumos, maquinários equipamentos e veículos de transporte, pode facilitar a comercialização dos produtos da agricultura familiar (SIMÃO et al., 2015; SARON et al., 2017).

Nesse cenário onde a agricultura familiar esta associada a desenvolvimento local, segurança alimentar, acesso ao mercado e desenvolvimento do meio rural, as políticas públicas são ferramentas fundamentais (SALGADO et al., 2016; CUNHA et al., 2017; BRASIL, 2017). A exemplo disso, fala-se da destinação obrigatória dos recursos financeiros das Instituições públicas federais, que devem destinar no mínimo $30 \%$ à gêneros alimentícios oriundos dos agricultores familiares.

Os entrevistados foram questionados sobre as vantagens e desvantagens. A I2 não mencionou vantagens (em qualidades e quantidade), verificando-se maior gasto financeiro para suprir a demanda do restaurante realizando a compra dos produtos de outros fornecedores. A entrevistada I3 disse não ver desvantagem neste tipo de contratação, podendo ser esse recurso um investimento no âmbito socioeconômico para o país.

Desta forma, diante o contexto da pesquisa e das análises referentes ao quadro 1 que expõe as principais vantagens e desvantagens apontadas pelas Instituições entrevistadas (I1, I2 e I3), suas pretensões em lançar outros editais e sugestões quanto ao desencadeamento do programa, principalmente no que condiz com a modalidade $\mathrm{Cl}$.

QUADRO 1. Posicionamento das Instituições quanto à aquisição de gêneros alimentícios via PAA-CI.

\begin{tabular}{|c|ccc|}
\hline \multicolumn{3}{|c|}{ Instituições que lançaram edital para Aquisição de Alimento via PAA-Cl } \\
\hline Instituição & Compras via PAA-Cl & Existe a pretensão da & Qual seria a proposta \\
\hline ENCICLOPÉDIA BIOSFERA, Centro Científico Conhecer - Goiânia, v.15 n.28; p.738 & 2018 \\
\hline
\end{tabular}




\begin{tabular}{|c|c|c|c|c|}
\hline & $\begin{array}{l}\text { Vantagens na } \\
\text { Compra via PAA }\end{array}$ & Desvantagens & $\begin{array}{c}\text { realização de outras } \\
\text { compras via a } \\
\text { modalidade } \mathrm{Cl} ?\end{array}$ & $\begin{array}{c}\text { para maior eficiência } \\
\text { do Programa? }\end{array}$ \\
\hline I1 & $\begin{array}{l}\text { Qualidade dos } \\
\text { produtos }\end{array}$ & $\begin{array}{c}\text { Demanda para compra } \\
\text { em quantidade pequena } \\
\text { comparada com as outras } \\
\text { aquisições realizadas na } \\
\text { instituição }\end{array}$ & $\begin{array}{l}\text { Só realizarão a compra } \\
\text { via modalidade se } \\
\text { houver recurso para o } \\
\text { cumprimento da lei }\end{array}$ & $\begin{array}{c}\text { Melhoria na Logística } \\
\text { para a entrega dos } \\
\text { produtos }\end{array}$ \\
\hline 12 & $\begin{array}{l}\text { Operacionalmente } \\
\text { não houve vantagens }\end{array}$ & $\begin{array}{l}\text { Entrega fora do prazo; } \\
\text { Qualidade e quantidade } \\
\text { não atenderam a } \\
\text { expectativa do solicitante }\end{array}$ & $\begin{array}{c}\text { Só realizarão a compra } \\
\text { via modalidade se } \\
\text { houver recurso. Para o } \\
\text { cumprimento da lei }\end{array}$ & $\begin{array}{l}\text { Maior atividade de } \\
\text { Políticas Públicas, } \\
\text { como infraestrutura } \\
\text { oferecida aos } \\
\text { produtores, com a } \\
\text { disponibilidade de } \\
\text { transporte oferecido } \\
\text { pelos órgãos do } \\
\text { estado, prefeituras. }\end{array}$ \\
\hline 13 & $\begin{array}{l}\text { Qualidade dos } \\
\text { produtos }\end{array}$ & $\begin{array}{l}\text { Não foi verificado maiores } \\
\text { desvantagens, apenas o } \\
\text { valor atribuído aos } \\
\text { produtos da agricultura } \\
\text { familiar }\end{array}$ & Sim & $\begin{array}{l}\text { Maior apoio do } \\
\text { Governo, dos orgãos } \\
\text { públicos quanto a } \\
\text { assistência técnica } \\
\text { para melhores práticas } \\
\text { de produção e } \\
\text { logística para } \\
\text { execução do PAA. }\end{array}$ \\
\hline
\end{tabular}

Foram entrevistados também dois gestores de duas instituições, a 14 ainda não realizou chamada para adquirir alimento pelo programa PAA-Cl e a outra esta em processo licitatório (I5). A Chamada Pública é um forte instrumento que garante maior oportunidade para a agricultura familiar e a criação da modalidade $\mathrm{Cl}$ dentro do programa PAA, com dispensa de processo licitatório aumentando a oportunidade participativa, inserindo-a no mercado, possibilitando a ação de mercado com órgãos públicos como hospitais, forças armadas, presídios, refeitórios de creches, restaurantes universitários dentre outros (WFP, 2015).

Ambas as instituições dispõem de restaurante sendo que na 14 é demandada apenas uma refeição diária e na 15 três refeições diárias. As mesmas apresentam conhecimento do PAA, mas até o momento os alimentos fornecidos para estas não são produzidos por agricultores familiares. Estas instituições conhecem o decreto no 8.473, assim como o PAA e modalidade $\mathrm{Cl}$. Um dos representantes da 14 quanto interrogado relatou que existe a necessidade de maiores esclarecimentos quanto à legislação do PAA, o mesmo ainda afirmou que ainda visualiza ausência de incentivo à agricultura familiar, como maior apoio para a obtenção dos documentos/requisitos para que possam participar da chamada pública.

A 15 realizou o lançamento da chamada Pública no mês de junho deste ano, a sua representante mencionou encontrar dificuldades inicialmente para a realização da chamada sendo uma atividade nova. É importante citar a preocupação da Instituição em selecionar fornecedores que morem mais próximo à região metropolitana de Belém. Justificando-se tal preocupação devido os produtores familiares não possuírem transporte para entrega dos produtos. O representante da 14 afirmou que apresentam interesse em desenvolver edital para que possa ser realizada a compra por meio do PAA. 
A proximidade do produtor com o consumidor diminui gastos, já que as maioria dos produtores apresentam dependência na terceirização de transporte, por não dispor dos próprios veículos, tendo assim que custear a logística desde a sua propriedade rural até o local da entrega dos produtos (CONSTA et al., 2015; SIMÃO et al., 2015).

O estudo da produção e demanda local, torna-se fundamental para eficiência da Compra Institucional (MARTINELLI et al., 2015). Mas também, a identificação dos instrumentos mais adequados a serem utilizados, dependendo das situações especifica de cada agricultor, das cooperativas ou associações. Lemos e Lima (2014) e Salgado et al. ( 2017) apontam que o PAA necessita da ampliação de suas ações voltadas para o desenvolvimento local, considerando as disparidades existentes em termos culturais, econômicos e sociais, aplicando-se a problemática principalmente as regiões norte e nordeste do país.

\section{CONCLUSÃO}

Conclui-se que o PAA ainda é pouco acessado e, consequentemente, pouco distribuído pelo estado do Pará. Isso vale, neste caso, para a compra institucional.

Houve um crescimento no número de fornecedores do PAA, porém ainda é pouco expressivo o número de associação e cooperativas, principalmente as organizações de mulheres frente à dimensão da agricultura familiar no estado do Pará. Entre os fatores associados a este contexto podem ser mencionados: o acesso dos editais, a falta de informação sobre o programa, a inexistência de ações de extensão rural e políticas públicas.

Os problemas encontrados por algumas das instituições para operacionalização da política pública foram, principalmente a aspectos ligados a infraestrutura, como à entrega dos alimentos na data estipulada. Outra questão refere-se à qualidade dos alimentos, já que, não estava conforme as especificações da contratante. Estes associados a aspectos logísticos, operacionais e ao menor contato entre secretárias e os agricultores. Os avanços remetem-se a aplicação da legislação que esta sendo desenvolvida, mas ainda existe a necessidade de maiores articulações.

Assim seria importante parcerias entre os produtores e órgãos que ofereçam serviços de ATER. Articulações e Ampliação dos canais de comercialização, melhorias de infraestrutura para a decorrência da logística dos gêneros alimentícios e financiamento para investimentos em equipamento, insumos, viabilizando maior potencial produtivo, com maior diversidade de produtos de boa qualidade, possibilitando maior segurança alimentar e estabilização da renda dos trabalhadores do meio rural.

\section{REFERÊNCIAS}

BRASIL -Ministério do Desenvolvimento Social. Programa de Aquisição de Alimentos (PAA). Manual operativo. Modalidade compra com doação simultânea operação por meio de termo de adesão (2014). Disponível em: <http://www.mds.gov.br/webarquivos/publicacao/seguranca_alimentar/manualPAA.p df . > Acesso em: 14 set. 2018.

BRASIL -Ministério do Desenvolvimento Social. Relatório de Execução: Programa de Aquisição de Alimentos- Modalidade Compra Institucional, 2016. Disponível em: < www.mds.gov.br/webarquivos/arquivo/.../Relatorio_Execucao_PAA_Cl_2016.pdf > .Acesso em: 18 de Dez.2017. 
BRASIL, Banco Central do Brasil. Calculadora do cidadão. Correção de valores. Disponível em:

https://www3.bcb.gov.br/CALCIDADAO/publico/exibirFormCorrecaoValores.do?meth od=exibirFormCorrecaoValores >. Acesso em: 14 de set. 2018.

BRASIL. Lei o 12.512, de 14 de outubro de 2011. Altera as Leis no s 10.696, de 2 de julho de 2003, 10.836, de 9 de janeiro de 2004, e 11.326, de 24 de julho de 2006. Diário Oficial da União, República Federativa do Brasil, Brasília, 2011. Disponível em:

http://pesquisa.in.gov.br/imprensa/jsp/visualiza/index.jsp?jornal=1\&pagina=1\&data=1 7/10/2011 >. Acesso em: 10 de set. 2018.

BRASIL. Ministério do Desenvolvimento Social. Programa de Aquisição de Alimentos, 2018. Disponível em: <http://mds.gov.br/assuntos/segurancaalimentar/programa-de-aquisicao-dalimentos-paa/programa-de-aquisicao-dealimentos>. Acesso em: 10 set. 2018.

CAVALCANTI, N.T.F.; MARJOTTA-MAISTRO, M.C.; MONTEBELLO, A.E.S. O Programa de Aquisição de Alimentos (PAA): uma avaliação por regiões brasileiras no período de 2011-2014. Revista Nera, Presidente Prudente - SP, ano 20, n. 40, p. 225-245, $\quad$ Set-Dez. $2017 . \quad$ Disponível em:< http://revista.fct.unesp.br/index.php/nera/article/viewFile/4999/4039>. Acesso em: 10 jun. 2018.

CONAB, Companhia Nacional de Abastecimento. Segurança Alimentar, Programa de Aquisição de Alimentos - PAA. Disponível: $<$ http://www.mds.gov.br/segurancaalimentar/decom/paa/programa-de-aquisicao-dealimentos-paa> Acesso em 10 nov. 2017.

CONAB, Companhia Nacional de Abastecimento. Disponível: <http://www.conab.gov.br/conteudos.php?a=1125> Acesso em 10 jun. 2018.

COSTA, B.A.L.; AMORIM JUNIOR, P.C.G.; SILVA, M.G. As Cooperativas de Agricultura Familiar e o Mercado de Compras Governamentais em Minas Gerais. Revista de Economia e Sociologia Rural. Piracicaba-SP, v. 53, n. 1, p. 109-126, 2015. Disponível em:<http://www.scielo.br/scielo.php?script=sci_arttext\&pid=S010320032015000100109>. Doi: http://dx.doi.org/10.1590/1234-567818069479005301006.

CUNHA, W.A.; FREITAS, A.F.; SALGADO, R. J.S. F. Efeitos dos Programas Governamentais De Aquisição de Alimentos para a Agricultura Familiar em Espera Feliz, MG. Revista de Economia e Sociologia Rural. Piracicaba-SP, v. 55, n. 3, p. 427-444, 2017. Disponível em:< http://www.scielo.br/pdf/resr/v55n3/1806-9479-resr55-03-427.pdf> . Doi: http://dx.doi.org/10.1590/1234-56781806-94790550301.

IPEA. Instituto de Pesquisa Econômica Aplicada. Desenvolvimento Rural. In: IPEA. Políticas Sociais: acompanhamento e análise. Brasília, ํㅡㄹ, 2015. Disponível em:

$<$ http://www.ipea.gov.br/portal/images/stories/PDFs/politicas_sociais/bps_23_140720 15.pdf>. Acesso em: Acesso em 10 jun. 2018. 
LEMOS, S.M.; LIMA, I. S. O programa de aquisição de alimentos (PAA) como política pública para a agricultura familiar e o desenvolvimento local. Revista Brasileira de Economia Doméstica. Viçosa- MG, v. 25, n. 1, p. 069-092, 2014. Disponível: <https://www.oikos.ufv.br/index.php/oikos/article/download/143/186 >. Doi: 10.1590/S1982-45132013000300003.

MARTINELLI, S.S.; SOARES, P.; FABRI, R.K.; CAMPANELLA, G.R.A.; ROVER, O.J.; CAVALLI, S.B.; Potencialidades da compra institucional na promoção de sistemas agroalimentares locais e sustentáveis: o caso de um restaurante universitário. Segurança Alimentar e Nutricional. Campinas- SP, v. 22, n. 1, p. 558-573, 2015. Disponível: https://periodicos.sbu.unicamp.br/ojs/index.php/san/article/view/8641574 >. Doi: 10.20396/san.v22i1.8641574.

SALGADO, R.J.S.F.; TEIXEIRA, E.C.; CUNHA, W.A. Contribuição dos programas de compra institucional (PAA e Pnae) para a estabilização dos preços agrícolas em Minas Gerais. Revista de Estudos Sociais. Viçosa, v.18, n. 37, p. 22-41, 2016. Disponível: < periodicoscientificos.ufmt.br/ojs/index.php/res/article/view/3048 >. Doi: http://dx.doi.org/10.19093/res.v18i37.3048.

SALGADO, R.J.S.F.; SILVA, E.A.; FERREIRA, M.A.M. ; CUNHA, W.A.; SANTOS, L.F.; Focalização e Cobertura do Programa de Aquisição de Alimentos (PAA): avaliação de sua eficácia nas regiões brasileiras. Revista de Economia e Sociologia Rural. Piracicaba-SP, v. 55, n. 4, p. 661-678, 2017. Disponível: < http://www.scielo.br/scielo.php?script=sci_arttext\&pid=S0103-20032017000400661 >. Doi: http://dx.doi.org/10.1590/1234-56781806-94790550403.

SARON, F.A.; NEVES NETO, C. C.; HESPANHOL, A.N. As dificuldades de implementação dos programas de apoio à agricultura familiar no Brasil. Boletim de Geografia. Maringá - PR, v. 35, n. 1, p. 1-16, 2017. Disponível: < http://www.periodicos.uem.br/ojs/index.php/BolGeogr/article/view/30818>. Doi: http://dx.doi.org/10.4025/bolgeogr.v35i1.30818.

SIMÃO, G.L.; FREITAS, A.F.; SILVA, E.A.; BASTOS, B.R.N.; SALGADO, R.J.S.F.; AMODEO, N.B.P.; Políticas Públicas de desenvolvimento local e adensamento de capital social: análise do Programa de Aquisição de Alimentos (PAA) em quatro municípios de Minas Gerais. Revista de Administração da UFSM. Santa Maria RS, v. 10, n. 2, p. 288-306, 2017. Disponível: < https://periodicos.ufsm.br/reaufsm/article/view/16689>. Doi: $10.5902 / 19834659$ 16689.

WFP - World Food Programme. Modalidades de Compras Públicas de Alimentos da Agricultura Familiar no Brasil. Série Políticas Sociais e de Alimentação, v. 2, 2015. Disponível em:

http://www.mds.gov.br/webarquivos/publicacao/seguranca_alimentar/PAA_Instituci onal_Estudo2_modalidades_lowres.pdf>. Acesso em: 10 de Set. 2017. 